\title{
Analysis of Impacts of Land Use Changes in Kitengela Conservation Area on Migratory Wildlife of Nairobi National Park, Kenya
}

\author{
John K. M. Wandaka ${ }^{1} \&$ Francis M. Kabii ${ }^{2}$ \\ ${ }^{1}$ Deputy Director of Studies \& Principal Lecturer, Tourism Department, Kenya Utalii College, Kenya \\ ${ }^{2}$ Lecturer, Tourism Department, Kenya Utalii College, Kenya \\ Correspondence: John K.M. Wandaka (Ph.D), Tourism Department, Kenya Utalii College, P.O. Box 31052-00600, \\ Nairobi, Kenya. E-mail: wandakaj@gmail.com
}

Received: May 2, 2019; Accepted: May 29, 2019; Published: June 13, 2019

\begin{abstract}
Nairobi National Park (NNP) in Kenya was established in 1946 to conserve the abundance and diversity of wildlife in the Kitengela-Athi-Kaputei plains, from excessive exploitation. It is currently fenced except on the Kitengela side across the Mbagathi River due to the sub-division of the group ranches, which commenced in the 1980s, limiting access of wildlife to the migratory corridor and dispersal areas. This paper is based on a study conducted to assess the impacts of the resultant land use changes in the Kitengela dispersal area/ migratory corridor on the migratory fauna of NNP, and to identify appropriate mitigation measures. The findings indicated that increased human settlement, led to changes in land uses which resulted into multiple negative impacts on the migratory wildlife of Nairobi National Park, mainly due to loss of dispersal area and blockage of migratory routes, leading to wildlife confinement, decreased wildlife tolerance and increased incidences of human wildlife conflicts. Data analysis indicated decline in migratory wildlife population thus negative effect $(\mathrm{F}=, 6.066, \mathrm{p}<0.05)$. The findings also indicated that loss of migratory routes/dispersal area and reduced vegetation cover was regarded by $55 \%$ of the local community respondents as one of the main consequences of the land use changes resulting from the subdivision of the group ranches leading to decreased wildlife tolerance $(\beta=0.246)$ and wildlife confinement $(\beta$ $=0.371)$ in NNP $\left(\mathrm{p}=0.021,<0.05, \mathrm{~F}=2.678 ; \mathrm{R}=0.179, \mathrm{R}^{2}=0.032\right)$. The paper also discusses the mitigation measures for the longtime sustainability of the park, the dispersal area and migratory corridor, including holistic implementation of the Kitengela-Isinya-Kipeto Local Physical Development Plan, mapping and protection of the vital wildlife areas within the migratory range, including the wildebeest calving area in North Kaputiei.
\end{abstract}

Keywords: dispersal areas, human-wildlife conflicts, local community, migratory corridors, wildlife conservation lease programme

\section{Introduction}

The Kitengela-Athi Kaputiei plains ecosystem, located between Kajiado and Machakos Counties in Kenya, is rich in wildlife diversity and abundance. It forms part of the vast Maasailand ecosystem that straddles the KenyaTanzania border which has been described as the area that supports the most abundant wildlife populations on earth (Western, 2009). In the past, the migratory wildlife roamed freely within the ecosystem, and at times could move as far as Amboseli National Park, in the foothills of Mt. Kilimanjaro. Even after the establishment of NNP, the wildlife continued the migratory patterns, since by then the park was not fenced. All the areas surrounding the park served as its dispersal area, giving the park habitat the much needed period of recuperation. The wildlife hence traditionally migrated seasonally to the surrounding plains during the wet season, and returned to the park during the dry season (Nyeki, 1992).

The NNP is unique in that it is teeming with wildlife diversity, yet only 8 kilometers from the Nairobi Central Business District. Over 100 species of mammals and 400 species of birds have been recorded in the park. This at times, has led to human-wildlife conflicts, necessitating the fencing of the western, northern and eastern borders (which are currently heavily developed), to minimize the human-wildlife conflicts, leaving only the southern side, bordering the Mbagathi River, overlooking the Kitengela plains (Gichohi, 1996). However, most of the Kitengela migratory corridor and the Athi-Kaputiei plains dispersal area are virtually blocked from wildlife migration and dispersal due to increased human settlement (EAWLS, 2002).

The sub-division of the group ranches in the Kitengela-Athi-Kaputiei plains (Kitengela, North Kaputei, Embolioi, Olkinos and Kisaju), commenced in the mid-1980s, due to inefficient management by the local communities' 
leadership (EAWLS, 2002). Some of the original landowners have since used the land as collateral for the acquisition of capital for investment, while others have sold out to recent immigrants (Nkedianye et al., 2009). This land fragmentation has given rise to new types of land uses which are incompatible with wildlife conservation. Indeed, aerial observations of the area exhibit extensive commercial agriculture, and a lot of corrugated iron sheets structures, as opposed to the eco-friendly temporary manyattas (huts) structures constructed by the nomadic Maasai pastoralists, that would either be demolished, or disintegrate soon after the nomadic Maasai moved on with their livestock.

The area that has been available for unrestricted migratory wildlife movement is the stretch of privately owned sparsely populated land in the central Kitengela region, including the Sholinke plains, the riverine Acacia xanthophloea forest and the Kitengela wetland, is currently under threat for conversion to other land uses. In an effort to ensure availability of the dispersal area and migratory corridor, a local Non-Governmental Organization (NGO), Friends of Nairobi National Park (FoNNaP), initiated the Wildlife Compensation and Lease Programme (WCLP) in 2000 (Nkedianye et al., 2009), and entered into contractual arrangements with the land owners not to engage in land uses incompatible with wildlife, in return for monetary compensation to safeguard the migratory corridor (Mungai, 2003). However, this project covers only a small percentage of the land owners in the AthiKaputiei ecosystem, and unless it is made more inclusive, it may not achieve the desired impact. NNP, the only protected (legally gazetted as a national park) portion of the ecosystem, represents a mere $5 \%$ of the original AthiKaputiei ecosystem (Prins et al, 2000; Reto-o-Reto, 2009). Since the former dispersal areas are blocked except the Kitengela plains, the latter is therefore regarded as the park's lifeline (ibid). The impacts of the resultant ecosystem fragmentation, and hence introduction of different land uses on the migratory wildlife of NNP are analyzed in this paper.

\subsection{Literature Review}

\subsubsection{Importance of Dispersal Areas and Migratory Corridors in Wildlife Management}

In Kenya, between $65 \%$ and $80 \%$ of the large species of wildlife are found outside the protected areas (Ouko \& Marekia, 1996), and hence requires the area outside the national parks for dispersal and migration. The NNP is enclosed with an electric fence, except along the southern border with the Kitengela-Athi-Kaputiei plains dispersal area of approximately $2,500 \mathrm{~km}^{2}$ (Gichohi, 1996). This therefore underpins the importance of the Kitengela area for the annual wildlife dispersal and migration.

The most critical portion of the dispersal area consists of the 60,000 acres triangle within Kitengela and Olturoto locations marked by the NNP (north), Empakasi River (south), Athi River-Namanga Road (east) and the IsinyaKiserian Road to the west (Nkedianye, 2004; Muriithi, 2008). The Kitengela area is therefore an important dispersal area and migratory corridor through which over an estimated 20,000 wildebeest, gazelles, zebra, giraffes and other ungulates, in addition to various predators, pass as they seasonally move in and out of the park (Nkedianye, 2004; Muriithi, 2008).

The Kenya Wildlife Service (KWS) acknowledges that on private land, the landowners have the final authority for determining the most beneficial type of land use to them (KWS, 1996). This may include livestock rearing or crop cultivation, which may not be compatible with wildlife conservation (Wandaka, 2018). To mitigate this, partnerships can be enhanced between the local landowners and KWS, which may involve benefits sharing, and hence responsibilities. The National Environment Action Plan (NEAP) Report of 1994 noted the importance of the dispersal areas and migratory corridors in the preservation of protected areas, since the protected areas do not encompass complete natural ecosystems, and are therefore currently dependent on the land beyond the boundaries, which is under pressure for conversion to other land uses. The report recommended that there was need to enhance the involvement of the local community in wildlife conservation and ensure that the wildlife contributes to their welfare (MENR, 1994; Wandaka, 2006).

Despite its proximity to the heavily populated and developed city, the park has a high and diversified wildlife population, and hence popular with both local and domestic tourists. The park is the dry season refuge for the wildlife in the Kitengela -Athi-Kaputei Plains, and the migratory wildlife gather in the park during the dry season (KWS, 1996). To mitigate human-wildlife conflicts, an electric fence was erected around the park on the eastern, western and northern boundaries. The Mbagathi River forms the southern boundary of the park, which is not fenced, and hence allows access to the Kitengela conservation area, and the Athi-Kaputei plains (Prins et al., 2000; Wandaka, 2018). This underscores the vital importance of the Kitengela plains which has been described as the lifeline of NNP (Reto-o-Reto, 2009a), and hence the subject of this paper. 


\subsubsection{Land Use Changes and Confinement of Wildlife in Nairobi National Park}

The Maasai traditional nomadic lifestyle in the Kitengela-Athi-Kaputiei ecosystem had minimal negative environmental impacts, since they would leave certain areas, to allow rejuvenation, as they reared their cattle in other areas (Kaasha, 2001). The Government of Kenya, in an attempt to empower the Maasai people economically, embarked on land privatization in some parts of Maasailand in the 1960's. Cheeseman (2002) writes that this did not succeed because some Maasai after receiving the land title deeds quickly sold out to the immigrant agriculturalist communities, which is what the colonial government tried to avoid through the group ranches system. Furthermore, privatization hindered the mobility of the Maasai, which they had practiced for hundreds of years. This in turn led to increased sedentarization and consequently unsustainable utilization of the pastoral resources, which significantly reduced the carrying capacity for both domestic and wild herbivores, and other dependent fauna (Wandaka, 2012). The above factors have therefore resulted into the confinement of migratory wildlife in the park.

\subsubsection{Land Tenure Changes in Kajiado County}

Land tenure is the relationship, whether legally or customarily defined, among people, as individuals or groups, with respect to land (includes other natural resources such as water and pasture). The traditional African land tenure system defined an individual or community's property rights and access to land and resources (Food and Agricultural Organization (FAO) Website, 2015). The indigenous African pastoral land tenure system among pastoral groups regarded resources as common property. Under the resource management systems reflected by different user groups, user rights were dependent on birth, clan and kinship, and guaranteed access to pasture, water and other resources (Homewood et al., 2009). The boundaries were sometimes not well defined. In such communal tenure system, each member had a right to use independently the resources owned by the community, which included rights to livestock forage (ibid). Recent sub-division of group ranches in the Kitengela area has seen land ownership change from group ranches (owned by the clan) to individual ownership (Wandaka,2018).

The group ranches leadership often leased out the land or sold land for personal gain to the detriment of the ranch membership (Homewood, 2005; Homewood et al., 2009;) sometimes pressurized by powerful interests into ceding community resources for which they are the stewards (Mwangi, 2007(a,b,c); Igoe, 2007). Galaty (1999) reports that faced with such insecurity of tenure, many Maasai group ranches members preferred to sub-divide and get individual land title deeds rather than risk losing out altogether. This is supported by a study conducted in the Loitokitok Sub-County in Kajiado County where, for similar reasons, the local communities felt short-changed and opted for group ranches sub-division (Wandaka, 2006).

The European colonial administration often interpreted the absence of clear cut boundaries as a lack of legal framework, rather than a well-adapted system of resource tenure, evolved in the context of unpredictable and variable environments. The colonial administration therefore imposed their own legal frameworks derived from what they had developed from other colonized nations (Homewood et al., 2009), without due diligence of the implications. To create room for the establishment of the NNP, the local nomadic pastoralist Maasai, and farming communities were removed from their ancestral lands (Porteous \& Smith, 2001). This interfered with the traditional Maasai nomadic lifestyle, which was compatible with wildlife conservation, with minimal conflicts. Kitengela was thereafter divided into group ranches, some of which have since been sub-divided and sold off to immigrants, giving rise to land uses incompatible with wildlife conservation, hence increasing incidences of human wildlife conflicts (Wandaka, 2018).

This is emphasized by Morell (1996), who reports that when the British Colonial Government signed treaties with the Maasai in 1904 and 1911, the latter was forced to give up their northern grazing lands on the Laikipia escarpment and Mt. Kenya areas, and some of them subsequently settled in the Kitengela area. The author further reports that some of these lands have been sub-divided and sold to non-Maasai farmers and other immigrants, leading to forms of land use that are not compatible with wildlife habitation, including cultivation and dense settlement. From the foregoing, changes in land tenure in the study area have therefore resulted in a change of ownership from group ranches to private ownership, resulting in reduced acreage, increased human population and hence human-wildlife conflicts.

\section{Methodology}

The respondents in the Kitengela Conservation Area (KCA) were grouped into three representative strata, as described below. 


\subsection{Local Community}

These were the inhabitants within the greater Kitengela area including indigenous Maasai residents, and immigrants into the area, comprised of pastoralists, agro-pastoralists, businessmen and residents in the greater Kitengela area. Since the local community respondents in the Kitengela study area showed variation in terms of age, main occupation, geographical location, distance of residence from NNP, and duration of the stay within the locality, stratified random sampling was used, based on the main economic activity and location within the study area and distance from the NNP. This enabled accession of in-depth information rather than generalized information as per the specified parameters of the study (Mugenda \& Mugenda,2003).

\subsection{Conservation/Tourism Community and the Government Agencies}

This group was persons/bodies that manage and/or engaged in advocacy on wildlife conservation and tourism enterprises and /or offer fiscal and/or technical support to the community. These included KWS, and NGOs, such as FoNNaP, ACC, and Community Based Organizations (CBOs). The Government agencies included the local administration in the study area, education sector, and extension work in the area, in Isinya Sub-County and Kajiado County at large. Both random sampling and purposive sampling techniques were used to gather data from respondents with the required information, in line with the objectives and hypotheses of the study. Quota sampling enabled the researcher to target different levels.

\subsection{The Sample Size and Sampling Procedures}

The target population of the study was mainly the stakeholders within the Kitengela environs, from the above categories, which was estimated to be over 10,000 people (GoK, 2001). The sample size (individual respondents) was therefore determined by using the formula by Fischer et al (1983), which gave 387 respondents, but a sample size of 400 was preferred to include more indigenous respondents.

\subsection{Data Collection and Analysis}

Since building trusting relationships with the respondents enabling their free expression may take longer to develop, contact was made with the local administration, local leadership and opinion leaders, which facilitated meetings with community members. These contact persons helped determine the best processes, and methods to be used in acquiring information from the different stakeholders of Kitengela, and following new leads, where the need arose. Contact was also made with the NGOs, funding agencies and other stakeholders mentioned above. Data collection was spread to cover both rainy and dry seasons.

\section{Results and Discussion}

This section contains the results of the statistical analysis used in testing the hypothesized relationships among the study variables, which was aimed at assessing the impacts of the land use changes in Kitengela Conservation Area (KCA) on the migratory wildlife of NNP. It also describes the results of various exploratory data analysis which include impact of increased human settlement on land use whereby factors that contributed to land sub-division are presented. This is followed by the analysis of relationships between group ranches sub-division and human population whereby impact of change of land tenure on increase in human population in Kitengela is presented. This section also outlines the impacts of changing land uses on the migratory wildlife whereby impacts of subdivision of group ranches on migratory wildlife and impacts of increased human settlement on the environment are presented. The chapter also explicates the factors influencing migratory wildlife populations by outlining changes in population of migratory wildlife from 1984 to 2010.

\subsection{Impact of Increased Human Settlement on Land Use}

The hypothesis $\mathrm{NH}_{1}$ of the study stated that "Human settlement in the Kitengela area has not made any significant contribution to changes in land use". To investigate this, objective (i) of the study was, "to determine the extent of land use changes in the Kitengela area in from 1984 to 2010." The study therefore examined the factors that led to the change of land tenure from group to individual ownership (through the sub-division of the group ranches), and the factors that led to the increased human settlement in the Kitengela study area. The findings are discussed below.

\subsection{Factors that Contributed to Land Sub-Division}

The sub-division of group ranches in the study area resulted in change of land ownership from the group (owned by the clan) to individual. In the group ranch system, the user rights are vested upon the clan, and hence the bona fide members had free access to the resources at all times, with the exclusion of non-members. With individual ownership, the user rights are vested upon the individual owners' households, and hence exclude persons who are not members of the respective families. As discussed later, this was found to impact upon the lifestyles of the 
Maasai people, land uses, and the natural resources utilization within the KCA. With regard to the reasons why land tenure was transformed from previous group ranches to individual ownership, the respondents gave various opinions from a given choice of factors, which yielded the following results as indicated in Figure 1 below. The individual factors are discussed in the following subsections.

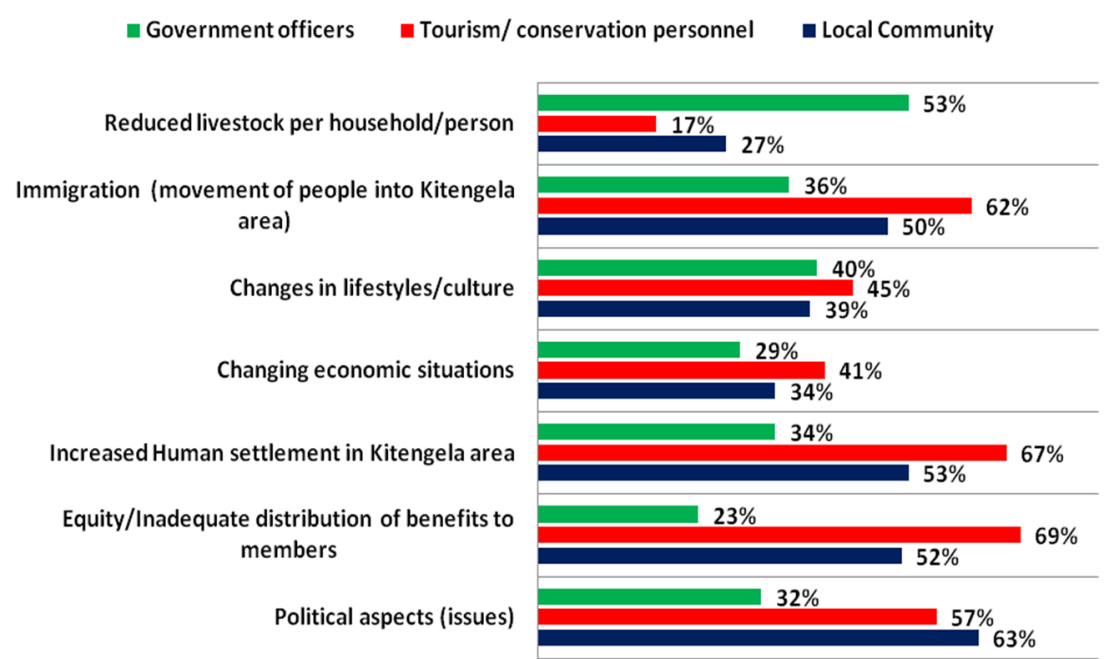

Figure 1. Comparative Analysis of Factors Contributing to the Sub-division of Group Ranches in Kitengela

\subsection{Political Issues}

From the respondents of the local community category, $63 \%$ regarded political issues as a very important factor that contributed to the sub-division of the group ranches through agitation, as opposed to $57 \%$ of the tourism/conservation personnel and $32 \%$ of the government personnel. This result supports the findings of a study conducted in the Kenyan Amboseli ecosystem (Wandaka, 2006) that revealed that political interests often took precedence in the management of group ranches thus alienating the local community members. The study identified a major demerit of the group ranch system of land ownership as the use of the said system as a political platform by aspiring politicians, who at times mobilized popular support for political interests rather than community welfare. From the foregoing, it is evident that political issues were an important factor that led to the sub-division of the group ranches, hence land use changes in the KCA.

\subsection{Equity/Inadequate Distribution of Benefits to Members}

The communal ownership of group ranches presumes that the bona fide members will share benefits accruing from their communal resources equitably. As shown in Figure 1 (above), the findings indicated that $52 \%$ of the local community respondents regarded equity issues as very important as opposed to $69 \%$ and $23 \%$ of the tourism /conservation and government respondents respectively. The three categories of respondents were generally in agreement that this was an important factor that contributed to the sub-division of the group ranches.

The findings corroborate studies conducted in other parts of Maasailand in Kenya. In the Amboseli ecosystem, it was found that issues on equity led to political agitation for the sub-division of the group ranches (Wandaka, 2012). Similarly, in the Maasai Mara ecosystem due to lack of local capacity to provide leadership, community representatives were easily derailed by stakeholders with conflicting interests. This eventually led to the agitation for sub-division to raise economic returns from land leases, curb exploitation of the poor members by the rich and the elite, and offer opportunities for using land title deeds as collateral to secure commercial loans (ACC, 2003; Waithaka, 2004).

\subsection{In-Migration/Increased Human Settlement in Kitengela Area}

The findings of the study indicated that $50 \%$ of the local community respondents regarded in-migration as very important, as compared to $62 \%$ and $26 \%$ of the tourism/conservation and government respondents respectively. At the same time, $53 \%$ of the local community respondents rated increased human settlement in Kitengela as a very important factor that leads to sub-division of the group ranches, as compared to $67 \%$ and $34 \%$ of the tourism/conservation and government respondents respectively. The in-migration resulted in increased human settlement, and was therefore identified as a key factor that led to the sub-division of the group ranches, hence land use changes. 
As aforementioned, the study area is located near the densely populated urban areas of Nairobi city, Athi River, Kitengela, Ongata Rongai and Kiserian. The study revealed that the influx of the population into these areas resulted in higher demand for land. The study area has also undergone several changes including rapid industrialization, such as the Export Processing Zone (EPZ), large scale intensive commercial farming, mining, quarrying and sand harvesting. After the sub-division of the group ranches, there was an influx of in-migrants into the study area since the land was further sub-divided into smaller land parcels. Land sales are common in the area, and land rates increased tremendously within a short duration as some investors bought land for prospective purposes (evident from the large fenced tracts of land in the study area), which led to the further sub-division into even smaller parcels of land. This corroborates earlier reports on ecosystem fragmentation in the Kitengela area, as detailed below.

Reid et al. (2008), and Nkedianye et al. (2009), report that land sales in Kitengela started occurring in the 1990s (after the sub-division), with the original owners selling parts of their land, as well as passing off their plots to inheritors. Many of the sales were to non-Maasai and farmers, the trend is common in Kajiado county, where 75\% of residents practicing cultivation being non-Maasai only a few years after the sub-division (Rutten, 1992; Nkedianye et al., 2009). In Kitengela, there is wide variation in land prices dependent upon the relative location, pasture potential, population density, relative distance to NNP, the nearest permanent water source, the nearest urban center, and distance to the tarmac. The increased human settlement in the Kitengela area has therefore severely reduced the acreage of the dispersal area and the migratory corridor of the plains to the south of the park which are important feeding areas during the wet season (Prins et al., 2000; Wandaka,2018). The findings of the study indicated that these changes have impacted negatively on the migratory wildlife through ecosystem fragmentation, which in turns block the migratory routes, and affects wildlife species distribution in the NNPAthi-Kaputiei ecosystem.

\subsection{Reduced Livestock per Household/Person}

The study revealed that there was a general decline in the per capita livestock ownership in the Kitengela area between 1997 and 2002, which was rated as a very important factor contributing to the sub-division of the group ranches, by $53 \%$ of the government agencies respondents, as opposed to only $27 \%$ and $17 \%$ of the tourism/conservation and government personnel respectively. In Maasailand, livestock rearing is a very important economic activity. The livestock reared in the study area are mainly cattle, sheep, goats, and donkeys for transportation. In a previous study conducted in the study area, all the respondents with the exception of two households owned livestock (Nkedianye et al., 2009). The Maasai pastoralists traditionally keep livestock as a means of wealth storage, and as a status symbol, and hence are not keen on reducing the per capita livestock. The findings from the study revealed that since formerly the livestock used to forage within the communally owned group ranch, the presumption was that the scenario would still prevail even after the sub-division.

This finding is in support of a study in the Maasai Mara ecosystem where despite land privatization conferring rights of land and its resources from the traditional communal management system to individual, those selling their land continued to regard other people's land as common property for livestock forage, oblivious of the fact that their rights to what they had always regarded as communal property had been lost (Waithaka, 2004). The reduced livestock per household was not regarded as a key factor leading to the sub-division of the group ranches. From the foregoing findings the null hypothesis that "Human settlement in the Kitengela area has not made any significant contribution to changes on land use" was rejected.

\subsection{Impacts of Changing Land Use on the Migratory Wildlife}

Hypothesis NH2 of the study stated that "The changing land uses in Kitengela have not impacted negatively on the park migratory fauna", while hypothesis NH3 stated that "The changes in land tenure in Kitengela have not affected the migratory wildlife of Nairobi National Park.". In addition, the same hypothesis (NH2) was in line with objective (i) which was to "Assess the extent of changes in land use on the migratory fauna". The study therefore sought to investigate how the change in land tenure (hence increased human settlement), has affected the Nairobi National Park migratory wildlife.

The respondents were therefore required to:

a. Indicate the impacts of group ranches sub-division on the migratory fauna

b. Rank impacts of migratory wildlife on the local community residing in the study area.

The percentage frequency and regression analysis on respondent's response on impacts of the sub-division of the group ranches on migratory wildlife were performed. The findings are discussed below. 


\subsection{Impacts of Sub-Division of Group Ranches on Migratory Wildife}

The NNP wildlife migrates seasonally to and from the park onto the Kitengela plains,

which serve as both dispersal area and migratory corridor. Even after the sub-division of the group ranches which commenced in the early $1980 \mathrm{~s}$, the fauna has continued the seasonal migratory patterns. The respondents were requested to indicate the impact of the sub-division of group ranches in the study area on the park migratory fauna. Table 1 below shows the comparative rating by the three categories of respondents as a very important factor.

Table 1. Comparative Impacts of the Sub-division of Group Ranches on Migratory Wildlife

\begin{tabular}{llll}
\hline Factors & Local Community \% & Tourism \& Conservation \% & Government \% \\
\hline i. Loss of migratory routes & 55 & 45 & 50 \\
ii. Loss of dispersal areas & 47 & 41 & 44 \\
iii. Increased human wildlife conflicts & 42 & 24 & 38 \\
iv. Decreased wildlife tolerance & 28 & 29 & 38 \\
v. Wildlife confinement in NNP & 43 & 38 & 44 \\
\hline
\end{tabular}

\subsection{Loss of Migratory Routes and Dispersal Areas}

NNP is fenced on all sides except the southern side overlooking the KCA plains, which is both a migratory corridor and dispersal area. As indicated in Figure 2 below, the migratory fauna passes through the study area (the only outlet since the park is fenced on all other sides) to access their wet season foraging grounds, further south in the migratory range. The respondents were requested to indicate the ranking on a Likert scale of the importance of the loss of migratory routes and dispersal areas due to land use changes resulting from the sub-division. From Table 1 above, $55 \%$ of the local community respondents regarded this factor as very important, as compared with $45 \%$ and $50 \%$ of the tourism/conservation and government respectively. In comparison, $47 \%, 41 \%$ and $44 \%$ of the local community, tourism/conservation and government respondents respectively regarded the loss of dispersal areas as a very important consequence of the sub-division of the group ranches in the Kitengela area.

The above observations can be attributed to the increased settlement in the dispersal area. The findings indicated that loss of migratory routes/dispersal area was regarded as a very important consequence of the sub-division of the group ranches. After the change of land tenure from group to individual ownership, and hence the sub-division, the land was further sub-divided into smaller parcels of land. These were often sold to the in-migrant communities for farming and residential purposes. The smaller parcels of land were subsequently fenced (both ordinary and electric) to minimize human-wildlife conflicts in terms of crop damage, livestock predations and threat to human life. These barriers consequently blocked the wildlife migratory routes

\subsection{Increased Human-Wildlife Conflicts}

The human population in the KCA increased significantly after the change of land tenure from group to individual ownership. As shown in Table 1 above, only $42 \%$ of the local community respondents, as compared to $24 \%$ and $38 \%$ for the tourism/conservation and government personnel respectively, ranked increased human-wildlife conflicts (human to wildlife) as a result of the sub-division of the group ranches and hence the resultant increase in human population as a very important factor. Before the change of land tenure, the Maasai community coexisted with wildlife in the study area. The findings of the study indicate that the KCA still remained an important dispersal area cum migratory corridor for NNP wildlife. Most of the areas under large scale cultivation, in-migrant settlement, and industrialization are fenced, to mitigate the human-conflicts.

The study further revealed that in recent times, due to ever decreasing acreage for dispersal and migration, increasing human population and changing economic situations, the human-wildlife conflicts are increasing, resulting into the retaliatory killing of what is perceived as "vermin" wildlife by the residents, as was the case on night of $20^{\text {th }}$ June 2012 when Maasai morans (warriors) killed six lions in an operation dubbed Linda Ng'ombe (protect the cows), and vowed to kill more until the government either fenced the park and compensated them for the losses, which the villagers claimed ran into millions of Kenya shillings (Odongo, 2012). The findings of the study indicate that the human-wildlife conflicts were relatively important consequences of the changes in land tenure, hence the increased frequency of incidents.

\subsection{Decreased Wildlife Tolerance}

As indicated in Table 1 above, only $28 \%$ of the local community respondents ranked decreased wildlife tolerance as a very important consequence of the sub-division of the group ranches. In comparison, $29 \%$ and $38 \%$ of the 
tourism/conservation respondents and Government personnel ranked decrease wildlife tolerance as a very important factor. This study identified two main factors why, despite the existence of the conflicts, the local community still displayed a moderate wildlife tolerant attitude: the Maasai traditionally coexisted with wildlife with minimal conflicts; and several NGOs active in the area are engaged in capacity building to create awareness and appreciation regarding the wildlife; furthermore, NGOs such as FoNNaP and Wildlife Direct operate a Wildlife Conservation and Lease Programme (WCLP) and the consolation programme, which aims at mitigating the conflicts through contractual lease of land, compensation for wildlife damage, and capacity building. The scheme, however covers only a fraction of the resident land owner households, hence needs to be more inclusive, since those respondents not covered by the project feel disenchanted and expressed the desire for inclusion into the programme.

\subsection{Wildlife Confinement in Nairobi National Park}

The respondents were required to relate the sub-division of the group ranches in the study area, hence changes in land use with the confinement of wildlife in NNP. The findings indicated that only $43 \%$ of the local community respondents as compared to $38 \%$ and $44 \%$ of the tourism/conservation and government personnel rated the issue as very important. Despite the sub-division of the group ranches, the park fauna still accesses the dispersal area for forage, though not in the large herds previously encountered in the Kitengela region. The researcher observed that the wildlife is still found in the park adjacent areas of Empakasi and Sholinke even during the dry season. However, the wildlife could not readily access their former range including the wildebeest calving area in north Kaputiei. In addition, the respondents reported a general decline in populations of migratory wildlife reaching their former wet season range further south, the wildlife is more abundant in the vicinity of the NNP. This was corroborated by a joint study between KWS and Colorado State University, USA, with collared wildebeests that indicated inability of the tagged animals to reach their migratory range including the wildebeest calving area (please refer to Figure 2 below).

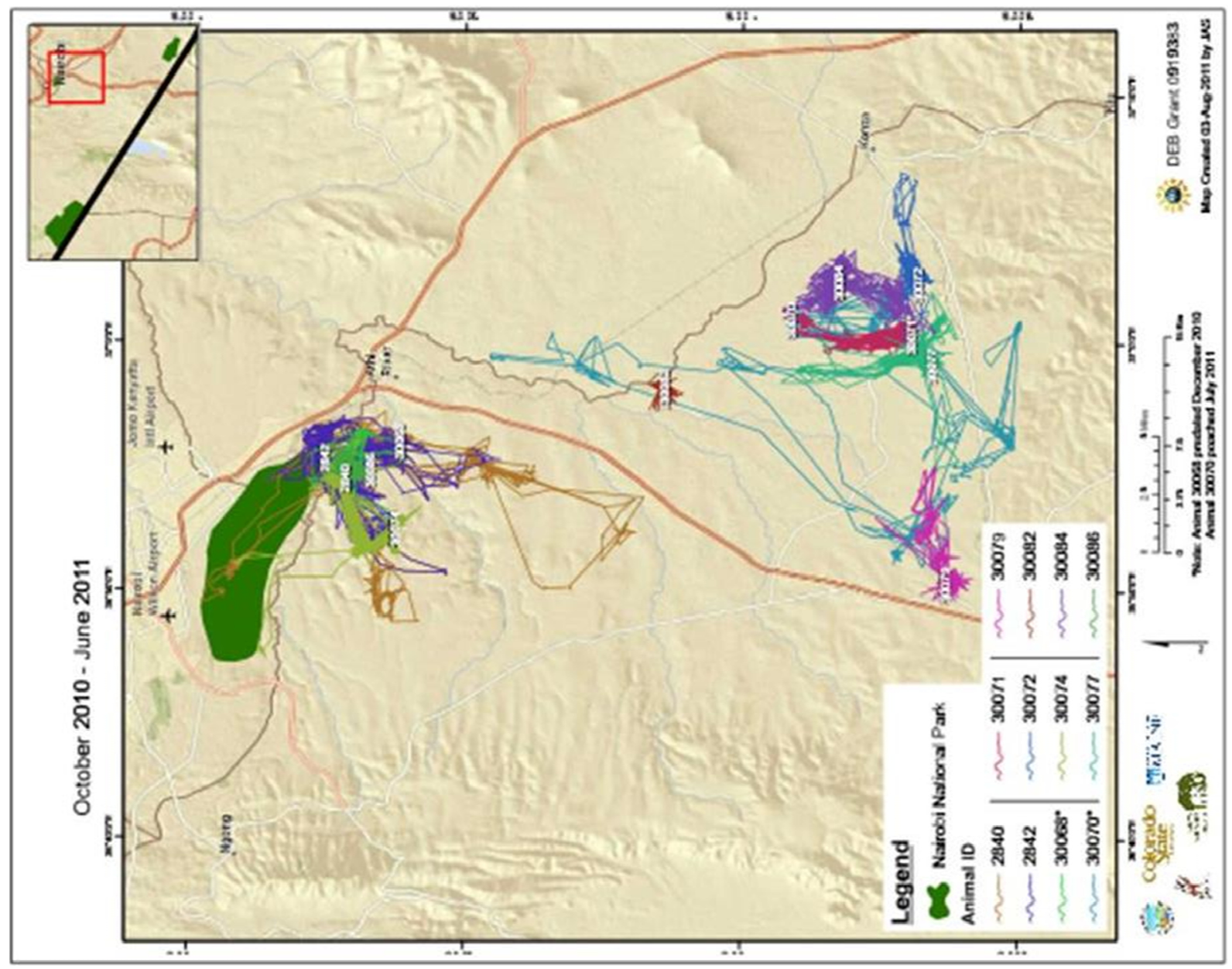

Figure 2. Migratory Wildlife Confinement due to Barriers Caused by Increased Human Settlement (Source: Colorado State University, 2012) 


\subsection{Regression Analysis: Impacts of Sub-Division of Group Ranches and Land Use Changes on Migratory Wildife Populations}

To establish the relationship that exists between the migratory wildlife and the increased human settlement, hence change in land uses, the former was treated as the dependent variable captured in the questionnaire by the question: "Has the population of migratory wildlife declined significantly from 1984 to 2010?" While the independent variable (explanatory) was captured by changes in land tenure and increase in human population within the dispersal area.

The research captured land tenure system in the questionnaire over the period 1984 to 2010. Land tenure has changed from group ranch to individual ownership. The factors that led to the sub-division of the group ranches were political aspects (issues), equity issues and inadequate distribution of benefits to members, increased human settlement in Kitengela area, changing economic situations, changes in lifestyles/culture, in-migration into Kitengela, and reduced per capita livestock.

In analyzing the relation between migratory wildlife and increased human settlement in terms of the land tenure system, the following results were obtained from the Analysis of Variance: The regression analysis structural model fitted was significant ( $\mathrm{p}=0.021, \mathrm{~F}=2.678, \mathrm{df}=5, \mathrm{R}=0.179, \mathrm{R}^{2}=0.032$ ). This model accounts for $3.2 \%$ of the variance in significant decline of population of migratory wildlife. This means that that at least one of the independent variables is a significant predictor of the dependent variable (the declined population of migratory wildlife (wildebeest) from 1984 to 2010.

Table 2. Analysis of Impact of Group Ranches Sub-division on Migratory Wildlife

\begin{tabular}{llllll}
\hline Variable & $\mathrm{B}$ & $\mathrm{SE}$ & $\boldsymbol{\beta}$ & $\mathrm{t}$ & sig. \\
\hline (Constant) & 70.579 & 12.944 & & 5.453 & 0 \\
1. Loss of migratory routes & -0.052 & 0.154 & -0.024 & -0.338 & 0.735 \\
2. Loss of dispersal areas & -0.053 & 0.112 & -0.026 & -0.472 & 0.637 \\
3. Increased human wildlife conflicts & -0.599 & 0.291 & -0.196 & -2.061 & $\mathbf{0 . 0 4 0 * *}$ \\
4. $\quad$ Decreased wildlife tolerance & 0.246 & 0.195 & 0.103 & 1.259 & 0.209 \\
5. $\quad$ Wildlife confinement in Park & 0.371 & 0.138 & $\mathbf{0 . 1 8 4}$ & 2.678 & $\mathbf{0 . 0 0 8} * * *$ \\
\hline
\end{tabular}

$\mathrm{R}=0.505 ; \quad \mathrm{R}^{2}=0.255 ; \quad$ F-value $=2.678$

Note: $* * * \mathrm{p}<.01, * * \mathrm{p}<05, * \mathrm{p}<.10$

The review of the above shows that:

$Y=\beta_{0}+\beta_{1} X_{1}+\beta_{2} X_{2}+\beta_{3} X_{3}+\beta_{4} X_{4}+\beta_{5} X_{5}$

$\boldsymbol{\beta}_{0}$ is the Constant

$\boldsymbol{\beta}_{1} \ldots . . . \boldsymbol{\beta}_{5}$ : Respective values of $\mathrm{B}$ which are the unstandardized coefficients use in the prediction and interpretation.

$\boldsymbol{Y}=$ has the population of migratory wildlife (wildebeest) declined significantly in the last 30 years? (Decline in population of migratory of wildlife).

$\mathrm{x}_{1}$ : Loss of migratory routes

$\mathrm{x} 2$ : Loss of dispersal areas

х3: Increased human wildlife conflicts

$\mathrm{x} 4$ : Decreased wildlife tolerance

xs: Wildlife confinement in Park

After regressing the structural model to establish the relationship that existed between migratory of wildlife and increased human settlement in terms of land tenure system the following were forth coming:

From the structural model, it was established that the following parameters:

$\mathrm{X}_{1}$ : Loss of migratory routes; $\mathrm{X}_{2}$ : Loss of dispersal areas and $\mathrm{X}_{3}$ : Increased human wildlife conflicts showed (negative relationship observed) indicated an inverse relationship between population of migratory wildlife and human settlement in terms of land tenure system.

On the other hand: 
Decreased wildlife tolerance (X4) and wildlife confinement in Nairobi National Park( $\left.\mathrm{X}_{5}\right)$ showed a positive relationship with a high coefficient of 0.246 and 0.371 respectively.

A review of the regression coefficients reveals that only one variable (wildlife confinement in the park) has positive impacts on decline in population of migratory of wildlife and significant at $1 \%$ level, when controlling the other variables in the equation. The beta weights $(\beta=0.184)$, indicate that wildlife confinement in park has the strongest impact on decline in population of migratory of wildlife. In interpreting the structural model, it was observed that a unit increase in the loss of migratory routes automatically leads to a decline in the population of migratory wildlife by a coefficient value of negative 0.052 (i.e. 5.2\%). A unit increase in wildlife tolerance will lead to an increase in migratory wildlife by +0.246 . While a unit increase in wildlife confinement in NNP, will lead to decline in migratory wildlife by 0.371 or $37.1 \%$.

\subsection{Hypothesis Testing}

The hypothesis (NH2) of the study stated that "The changing land use patterns in Kitengela have not impacted negatively on the park migratory fauna", while the hypothesis NH4 states that "The changes in land tenure in Kitengela have not affected the migratory wildlife of Nairobi National Park". From the analysis, the findings were therefore not in support of the hypotheses (NH2 and NH4) of the study, hence rejection of the hypotheses.

\subsection{Reduced Vegetation Cover and Access to Pasture for Migratory Wildlife}

Declining vegetation cover is generally regarded as a consequence of land use changes which often lead to increased human population in areas that were previously sparsely populated. The study sought to investigate whether the land use changes, hence increased human population in the study area had impacted negatively on the vegetation cover and access to pasture for the migratory fauna.

\section{a. Reduced vegetation cover}

As shown in Table 1, 55\% of the local community respondents rated this aspect as very important, as compared to $43 \%$ and $47 \%$ of the tourism /conservation and government employee's categories respectively. Field observations corroborated the satellite imagery of the study area, which showed marked changes in the vegetation cover from 1984 to 2010 (see Figures 3 A and B, showing land cover changes in the Kitengela study area between 1984 and 2010, below).

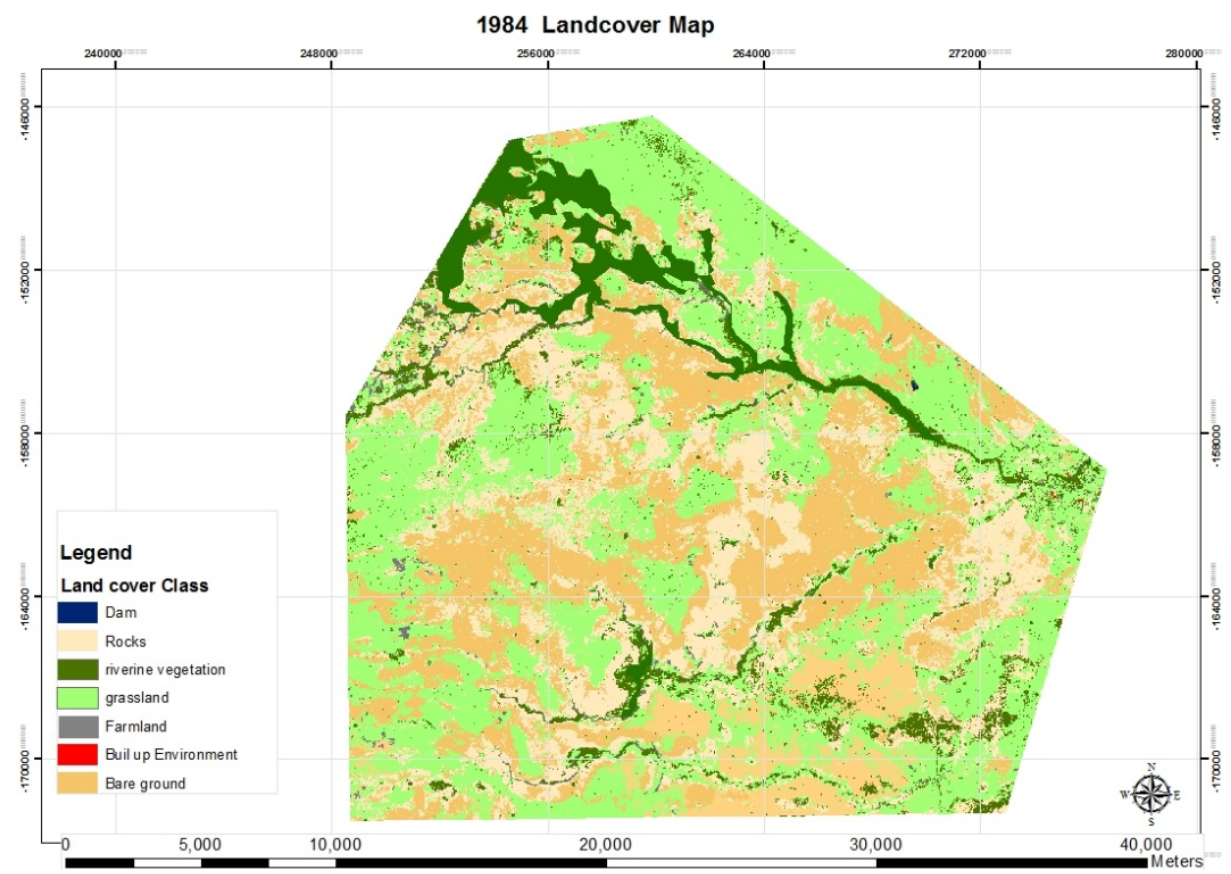

Figure 3A. Kitengela Land Cover Map Before Sub-division of Group Ranches 1984

Source: RCMRD, 2013 


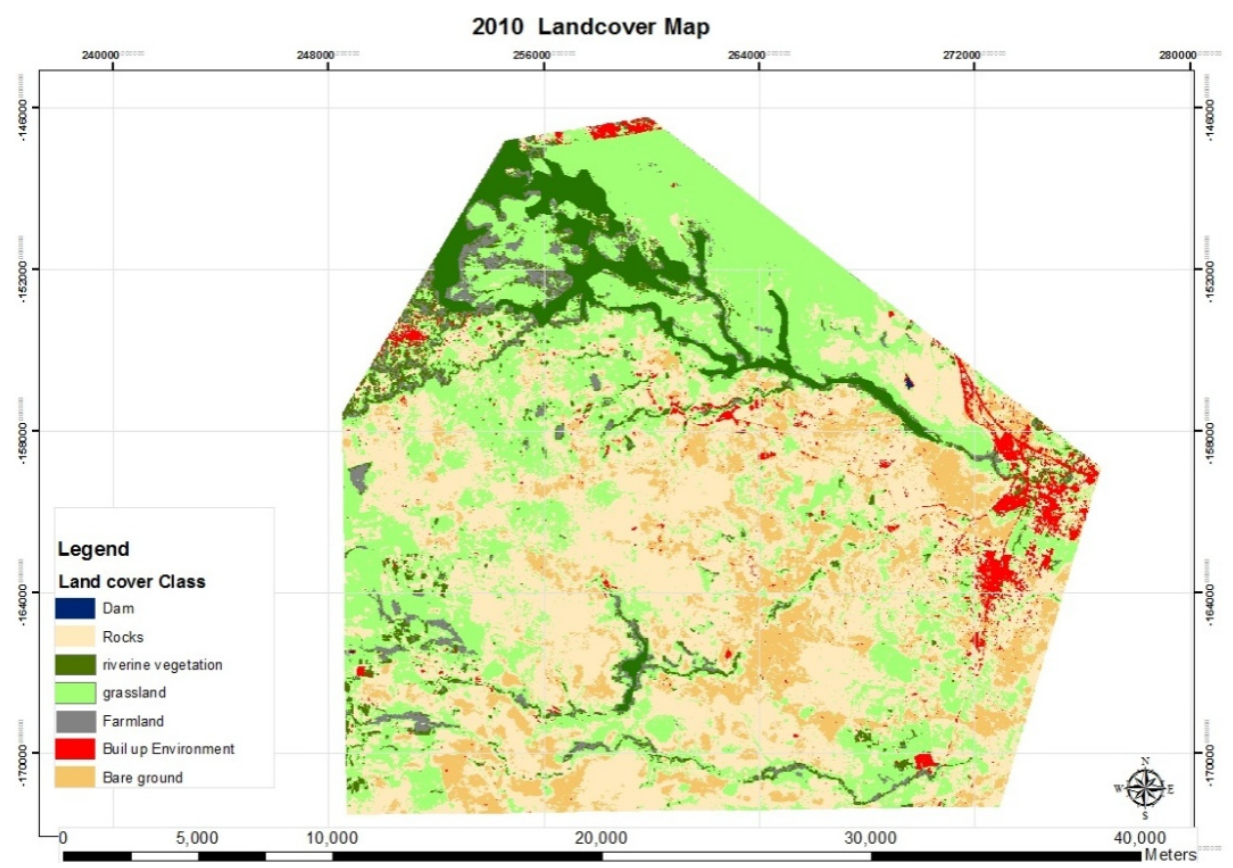

Figure 3B. Kitengela Land Cover Map -2010 (Source: RCMRD, 2013)

Table 3. Summary of Kitengela Land Cover Changes (1984 to 2010)

\begin{tabular}{lllll}
\hline Land cover category & Year & \multicolumn{2}{c}{ Variance $\left(\mathrm{km}^{2}\right)$} & \\
\cline { 2 - 3 } & 1984 & 2010 & & \\
Grassland & 174.94 & 80.24 & -94.70 & -54.13 \\
Water(wetlands/dams) & 0.09 & 0.06 & -0.03 & -33.3 \\
Riverine vegetation & 211.18 & 38.79 & -172.39 & -81.63 \\
Farmland & 0.21 & 39.05 & +38.84 & $+18,495.24$ \\
Bare ground & 103.39 & 120.48 & +17.09 & +16.53 \\
Built up Area/Tarmac & 15.26 & 55.15 & +38.89 & +261.40 \\
Rocks & 45.98 & 217.28 & +171.30 & +268.42 \\
\hline
\end{tabular}

The findings indicate that there was significant decline in natural vegetation cover (grassland $-54.13 \%$; riverine vegetation $-81.63 \%$ ); during the same period (1984 to 2010) the study area experienced significant increase in human settlement due to changes in land use (built up area/tarmac $(+261.40 \%)$ and farmland $(+18,495.24 \%)$. This has been as a result of clearance of vegetation for settlement, construction materials, agriculture, and household needs such as fuel wood and charcoal. The latter is often sold outside the study region in the nearby urban areas. Mitigation measures for the above include capacity building for the local community including use of energy efficient jikos (wood stoves), afforestation and reforestation. In addition, there was ecosystem fragmentation through sub-division and barriers to migration in the study area.

\section{b. Reduced access to pasture}

The respondents were required to rank the importance of increased human settlement as a factor affecting migratory wildlife through reduced access to pasture. As shown in Table $1,47 \%$ of the local community respondents rated the factor as being very important as compared to $52 \%$ from the tourism/conservation category and $59 \%$ of the government personnel category. This was corroborated by the data derived from the satellite imagery (Figures 3 and B, and Table 3), which indicated significant decline in natural vegetation cover as discussed above. With the increasing population, and erection of barriers, the migratory routes are becoming blocked restricting the migratory wildlife access to the feeding grounds and also the wildebeests' calving area in the southern parts of the KCA, indicates a significant decline in vegetation cover (grasslands and riverine vegetation) and corresponding increase in built-up areas and farmland over the study period. In addition, field observations indicated ecosystem fragmentation through sub-division and fencing and hence blockage of wildlife migratory routes. The above changes in natural vegetation cover hence reduced access to pasture can be therefore directly 
attributed to the land use changes, which was a consequence of land tenure changes hence increased human settlement.

\subsection{Barriers to Wildlife Migration}

From the data collected, $51 \%$ of local community respondents ranked barriers to wildlife migration as very important. In comparison, $60 \%$ and $40 \%$ of the tourism/conservation and government respondents' categories respectively ranked the aspect as very important. From the findings it is evident that barriers to wildlife migration are a significant impact as a result of change in land uses in Kitengela region.

In the KCA, barriers to wildlife migration are mainly fences protecting farmland, homesteads, and land parcels owned by absentee landlords, and also quarries, industries, and settlement. The main types of fencing include electric, barbed wire, chain-link, wire mesh, traditional hedge and thorn bush, and sometimes a combination of these methods. The study found that the land value in the Kitengela area had appreciated considerably in the recent past, mainly due to the large numbers of immigrants drawn by settlement, engagement in business ventures and employment opportunities, due to the industrial development in the neighbourhood including the Export Processing Zone (EPZ), several industries including several cement factories, as well as several tertiary educational institutions. The barriers erected to mitigate human-wildlife conflicts (and by the absentee landlords), has reduced access to pasture as well as blocking the traditional migratory routes between the wet and dry season refuge zones for the migratory wildlife (Nkedianye et al., 2009).

\subsection{Mitigation Measures to Challenges Facing Migratory Wildlife in Kitengela Conservation Area due to Land use changes}

The land sub-divisions led to the influx of in-migrants into the study area, and hence new types of land uses, in this area that was previously used for pastoralism and wildlife. Some of the said land uses were clearly incompatible with the migratory and dispersal patterns of the wildlife. The study identified the following as appropriate mitigation measures:

i. The government through the KWS should review and ensure full participatory implementation of the Kitengela-Isinya-Kipeto Local Physical Development Plan, 2008-2018 (Ministry of Lands, 2010), to control land use and fragmentation, and stop further land sales/sub-division in the migratory corridor. In addition, zonation of the land (based on the plan) should be implemented, with clearly defined areas for settlement, and restriction of any further human settlement along the migratory corridor and NNP vicinity, to avail land for the migratory wildlife. To ensure sustainability, this should be backed with enactment/implementation of legal and policy framework regulating land sales, sub-division, fragmentation and agricultural activities along the migratory corridor.

ii. KWS to lease /buy land from locals for dispersal /migration or enter into contractual agreements with the local land owners to avail land for use by migratory wildlife. Members of the local community hosting wildlife on their land should be compensated at competitive rates.

iii. Sharing of benefits accrued from wildlife with the local community; this would be the incentive for the latter to set aside land for wildlife.

iv. The mapping and clear definition and preservation of the crucial sections of migratory routes and dispersal areas such as the wildebeests' calving area, watering points and creation of buffer zones to ensure preservation of the same.

v. Capacity building among the local community on appropriate land uses compatible with wildlife, especially in the migratory corridor and crucial sections of the dispersal area.

vi. Legal and policy framework regulating land sales, sub-divisions, and land uses incompatible with wildlife conservation in dispersal and migratory corridor areas.

\section{Conclusions}

The continued existence of any national park or reserve in its natural state is heavily dependent upon the availability of wildlife dispersal areas, without which the parks may require intensive management (MENR, 1994; Wandaka, 2012). As aforementioned, NNP, which constitutes only 5\% of the original Athi-Kaputiei ecosystem, is the only legally protected area of the rangeland through which the migratory wildlife freely moved in the past (Prins et al., 2000). The former migratory range is blocked on all sides except the southern side across the Mbagathi River and onto the Kitengela plains. Since the park is not large enough to sustainably contain the abundant wildlife all year round, the Kitengela plains are literally the park's lifeline (Reto-o-Reto,2009b), and if unavailable to the 
migratory wildlife through unplanned development and increased human settlement, NNP will become an "island", and its relatively small size will be unable to host the large and diverse populations of wildlife.

The study revealed that the sub-division of the group ranches, and the resultant changes in land uses, led to the increased human settlement and hence a rapid increase in population within the study area; this impacted negatively on the migratory wildlife of NNP. These impacts include the blockage of migratory routes, considerable decrease in the acreage of the dispersal areas and the migratory corridor, increased human-wildlife conflicts, resulting to increased wildlife confinement in the vicinity of the park, since they could not reach their former migratory range. The above were further compounded by other resultant impacts on the local community which included increased competition for pasture, predation of livestock, crop and property destruction, threat to human life, and disease transmission to livestock, all these leading to decreased wildlife tolerance, and increased incidences of killing of wildlife.

The findings from the study revealed that the major factors that led to the change of land tenure (hence land uses) from group to individual ownership included political factors (agitation), equity issues pertaining to the inequitable distribution of benefits to the members of the respective group ranches, and increased human settlement resulting due to in-migration into the study area. Other factors that contributed but to a lesser extent, were the changing economic situations, changes on lifestyle and culture and reduced per capita livestock in the study area. These led to multiple negative impacts on the migratory wildlife of Nairobi National Park as discussed in this paper.

With the increased human settlement resulting from the sub-division of the group ranches, several new types of land uses were introduced into the study area. These included intensive large scale farming, industrialization, extraction of construction materials, sand harvesting along the river courses, and settlement with the resultant factor of declined dispersal areas and blockage of migratory routes. This directly affected the migratory wildlife, which in turn led to the confinement of wildlife in vicinity of the park. The issues highlighted in this paper should be addressed through multi-stakeholder participatory approach for the sustainable management of the wildlife resources in the Athi-Kaputiei Ecosystem.

This led to the rejection of both hypotheses of the study that NH1 and NH3 of the study that "Human settlement in the study area has had no significant impacts on the migratory wildlife"; and that "Changing land uses in Kitengela have not impacted negatively on the migratory wildlife of Nairobi National Park".

The findings of the study also revealed that increased human settlement in the study area has further impacted negatively on migratory wildlife mainly in the following ways: the resultant rapid increase in human population has led to the loss of dispersal areas and blockage of migratory routes, which in turn has led to loss of pasture for the migratory wildlife. Since the mobility of the wildlife is curtailed, this has resulted in wildlife confinement in the park vicinity, high predation pressure for the park wildlife and increased incidences of human-wildlife conflicts in the study area. This in turn led to increasing frequencies of killing of wildlife in retaliation for livestock deaths, since the wildlife cannot move across to their former migratory range. To a lesser extent, increased human settlement has also led to less wildlife abundance and diversity in the study area. This therefore is contrast to hypotheses NH2 and NH3 that the "Changing land uses in Kitengela have not impacted negatively on the park migratory fauna" and that "Increased human settlement in the Kitengela dispersal area has not had significant impacts on the migratory fauna of Nairobi National Park", hence rejection of the hypotheses.

\section{Acknowledgments}

The authors wish to thank Prof. Steven G. Njuguna, of the Department of Environmental Sciences, Kenyatta University, Nairobi, Kenya for his invaluable support and guidance in conducting the doctoral study on which this paper is based. We are also grateful to Kenya Utalii College for the financial support, as well as Anne Kamau, Faith Waithira, Daniel Mwangi, Charity Wandia, Stephen Weru and Joy Kirathimo for their encouragement and support during the study.

\section{References}

African Conservation Centre (ACC). (2003). African Conservation Centre Field Studies. Diversity of Maasai Mara, ACC Conservation Bulletin, Linking Science, Conservation and People, 1(1).

Cheeseman, T. (2002). Conservation and the Maasai in Kenya: Trade-offs or lost mutualism? Policy Failure in Kenyan Conservation and Maasailands. Cheeseman Ecological Safaris. Retrieved September 4, 2016 from http://www.environmentalaction.net/kenya/kenya_policy failure.html

Colorado State University (United States of America). (2012). Retrieved September 22, 2016, from http://www.nrel.colostate.eduprojects gnu/imageStudy_Area.png 
East African Wildlife Society (EAWLS). (2002). A Survey to determine the availability of land for wildlife migration in the areas bordering Nairobi National Park, EAWLS, Nairobi.

Fischer, A., Laing, J., \& Stoeckel, J. (1983). Guidelines for Overcoming Design Problems in Family Planning Operations Research. Mediline, 16(2), 100-105. https://doi.org/10.2307/1965575

Food and Agricultural Organization (FAO) Retrieved October, 1, 2015from http://www.fao.org//y4307e05.htm

Galaty, J. (1999). Grounding pastoralists: Law, politics and dispossession in East Africa. Nomadic Peoples, 3(2), 56-73. https://doi.org/10.3167/082279499782409334

Gichohi, H. (1996). The Ecology of a truncated ecosystem: The Athi-Kapiti Plains, PhD Thesis, University of Leicester, Leicester, United Kingdom.

Government of Kenya (GoK). (2001). Population and housing census, vol.1.Counting our people for development. Population distribution by administrative areas and urban centres. Ministry of Finance and Planning. Nairobi, Kenya, 446pp.

Homewood, K. (Ed.). (2005). Rural resources and Local livelihoods in Africa. James Currey, Oxford and Palgrave. https://doi.org/10.1007/978-1-137-06615-2

Homewood, K., Kristjanson, P., \&Trench, P. C. (2009). Changing land use, livelihoods and wildlife conservation in Maasailand. In Homewood, K., Kristjanson, P., \& Trench, P. C. (Eds). (2009). Staying Maasai? Livelihoods, Conservation and Development in East African Rangelands, Springer Science + Business Media, New York. https://doi.org/10.1007/978-0-387-87492-0_1

Igoe, J. (2007). Human rights, conservation and the privatization of sovereignty in Africa- A discussion of recent changes in Tanzania. Policy Matters, 15, 241-254.

Kaasha, J. M. (2001). Ecotourism micro-enterprises a tool to conserve natural resources. Paper presented in the Micro and small enterprise development and associated natural resource use workshop, $21^{\text {st }}-22^{\text {nd }}$ February, 2001, International Council for Research in Agroforestry (ICRAF), Nairobi.

Kenya Wildlife Service (KWS). (1996). Wildlife human conflicts - Executive Summary. SAFARIWEB, Inter Green Services Limited, KWS, Nairobi. (Accessed 31 $1^{\text {st }}$ May, 2006).

Ministry of Environment and Natural Resources (MENR). (1994). National Environnemental Action Plan (NEAP), National Environment Secretariat, Nairobi.

Ministry of Lands. (2010). Kitengela-Isinya-Kipeto Local Physical Development Plan,2008-2018, Ministry of Lands (Department of Physical Planning), Nairobi.

Morell, V. (1996). Surrounded! - Civilization is encroaching on Nairobi National Park in Kenya- Nairobi's Wild Side. International Wildlife, 27(4), 38-44.

Mugenda, O. M., \& Mugenda, A. G. (2003). Research methods - Quantitative and qualitative approaches, ACTS Press, Nairobi.

Mungai, N. (2003). Nairobi National Park threatened by human-wildlife conflicts. Retroieved May 31, 2010, from http://www.ens-newswire.com/ens/mar2003

Muriithi, P. I. (2008). Human wildlife conflicts: A case study of peoples' participation in conflict resolution. Master of Arts in Sociology (Rural Sociology and Community Development) Thesis, University of Nairobi.

Mwangi, E. (2007a). Socio-economic change and land use in Africa: The transformation of property rights in Kenya's Maasailand. Macmillan, Palgrave. https://doi.org/10.1007/978-1-137-06659-6_8

Mwangi, E. (2007b). The Puzzle of group ranch sub-division in Maasailand. Development and Change, 38(5), 889-910. https://doi.org/10.1111/j.1467-7660.2007.00438.x

Mwangi, E. (2007c). Sub-dividing the commons: Distributional conflict in the transition from collective to individual property rights in Kenya's Maasailand. World Development, 35(5), 815-834. https://doi.org/10.1016/j.worlddev.2006.09.012

Nkedianye, D. (2004). Testing the attitudinal impact of a conservation tool outside a protected area: A case study of Kitengela Wildlife Consolation Lease Programme for Nairobi National Park, Kenya. Master of Arts (Rural Sociology and Community Development) Thesis, University of Nairobi.

Nkedianye, D., Radeny, M., Kristjanson, P., \& Herrero M. (2009). Assessing Returns to Land and Changing Livelihood Strategies in Kitengela, in Homewood, K; Kristjanson, P., \& Trench, P.C.(Eds); Staying Maasai? 
Livelihoods, Conservation and Development in East African Rangelands (p.128), Springer Science and Business Media, New York. https://doi.org/10.1007/978-0-387-87492-0_4

Nyeki, D. M. (1992). Wildlife conservation and tourism in Kenya. Jacaranda Designs, Nairobi

Odongo, P. (2012). Outrage as morans kill six lions in night of terror, Daily Nation, Thursday, $21^{\text {st }}$ June, 2012, Nation Media Group, Nairobi, Kenya

Ouko, E., \& Marekia, N. (1996). Land tenure and wildlife management, in Juma, C. \& Ojwang, J. (eds.), In Land We Trust, Initiatives Publishers, Nairobi.

Porteous, J. D., \& Smith, S. E. (2001). Domicile: The global destruction of home. McGill-Queen's Press. Retrieved September 25, 2016, from http://books.google.ie/books?id=6t_KSirfEnsC\&dq

Prins, H., Grootenhuis J. G., \& Dolan T. T. (2000) (Eds). Wildlife conservation by sustainable use. Kluwer Academic Press, Boston. https://doi.org/10.1007/978-94-011-4012-6

Regional Centre for Mapping of Resources for Development (RCMRD). (2013). Satellite Images of Kitengela Area. RCMRD, Nairobi.

Reid, R., Gichohi, H., Said, M. Y., Nkedianye, D., Ogutu, J., Kshatriya, M., Kristjanson, P., Kifugo, S., Agatsiva, J., Adanje, S., \& Bagine, R., (2008). In K. A. Gavin, N. T. Hobbs, R. Behnke, \& R. S. Reid, (eds.). Fragmentation of Arid and semi-arid lands. Kluwer Academic Press, London.

Reto-o-Reto. (2009a). Kitengela, Policy Brief No. 1, Reto-o-Reto, Nairobi.

Reto-o-Reto. (2009b). Kitengela transforming: Will pastoralists and wildlife survive? Policy Brief No.2, Reto-oReto. Nairobi.

Rutten, M. M. (1992). Selling wealth to buy poverty: The process of individualization of land ownership among the Maasai pastoralists of Kajiado District, Kenya, 1890-1990.VerlagBreitenbach Publishers, Fort Lauderdale, FL.

Waithaka, J. (2004). Maasai Mara-An ecosystem under siege: An African case study on the societal dimension of range and forage science. African Journal of Ecology: The Official Journal of the Grassland Society of Southern Africa, 21(2), 79. https://doi.org/10.2989/10220110409485838

Wandaka, J. K. M. (2006). Opportunities and challenges to effective community participation in ecotourism management in Kimana Communal Ranch, Kajiado District, Kenya, Masters of Environmental Studies (Science) Thesis, Kenyatta University, Nairobi.

Wandaka, J. K. M. (2012). Effective community participation in ecotourism management: opportunities and challenges in African rangelands. Lambert Academic Publishers, Saarbruk, Germany.

Wandaka, J. K. M. (2018). Human Wildlife Conflicts in Kenyan Rangelands, Lambert Academic Publishers, Saarbruk, Germany

Western, D. (1969). Land use in Maasai Amboseli Game Reserve: A case study; The Inter-Disciplinary Cooperation Institute for Development Studies Research Bulletin, No. 40; Institute for Development Studies, University of Nairobi, Nairobi.

Western, D. (2009). The future of Maasailand: its peoples and wildlife; in Homewood, K., Kristjanson, P., \& Trench, P. C. (Eds.). (2009). Staying Maasai? Livelihoods, Conservation and Development in East African Rangelands, Springer Science and Business Media, New York.

\section{Copyrights}

Copyright for this article is retained by the author(s), with first publication rights granted to the journal.

This is an open-access article distributed under the terms and conditions of the Creative Commons Attribution license (http://creativecommons.org/licenses/by/4.0/). 